\title{
Интеллектуалы и власть: еще один взгляд, или Аналитики и политики 135
}

\author{
Швырков А.И. \\ Брянский государственный технический университет, \\ Россия, 241035, Брянск, Бульвар 50 лет Октября, 7 \\ E-mail: aishvyrkov@rambler.ru
}

\begin{abstract}
Аннотация. В статье рассматривается проблема отношения интеллектуалов и власти. Во многом она, эта проблема, сводится к тому, что политики не слушают советов интеллектуалов. Почему же их не слушают? Возможно, это обусловлено существенной разницей в типе мышления тех и других. То, как мыслят интеллектуалы, преимущественно определяется политической теорией. Теория же характеризуется приматом системности, завершенности, подчиненности абстрактным, часто «идеальным» в моральном отношении принципам и целям. Последнее, очевидно, характерно для многих политических теорий. Что касается действий политиков, то они - по разным причинам - часто существенно отклоняются от тех параметров, которые задает теория. В свою очередь, интеллектуалы, как правило, не вовлечены в политическое действие в качестве а́кторов, то есть они не могут оценивать действия политиков иначе как с точки зрения теории. Например, на основании собственного опыта политической деятельности. В результате всего этого действия политиков часто приводят к неудовлетворительным как с точки зрения интеллектуалов (то есть с точки зрения теории и тех абстрактных принципов, на которых они основаны), так и самих политиков результатам. Выход из этой ситуации автор видит в том, что интеллектуалы должны в своих коммуникациях с политиками пожертвовать частью абстрактных принципов, на которых основаны теории, или не настаивать на их жестком соблюдении политиками. Им также следует попытаться уменьшить свои требования в отношении системности и последовательности действий политиков. Речь идет не о том, чтобы искусственно примитизировать свое мышление или «опускаться» в моральном отношении, речь идет о том, чтобы не ожидать и, главное, не требовать от общества в целом и политиков в частности большей строгости мышления и в следовании теории, чем та, на которую они в принципе способны.
\end{abstract}

Ключевые слова: интеллектуалы, политики, власть, теория, абстрактные принципы.

Для цитирования: Швырков А.И. 2021. Интеллектуалы и власть: еще один взгляд или Аналитики и политики. 48 (2): 486-496. DOI: 10.52575/2687-0967-2021-48-2-486-496.

\section{Intellectuals and Power: Another Look or Analysts and Politicians}

\author{
Aleksandr I. Shvyrkov \\ Bryansk State Technical University, \\ 750 let Oktyabrya Boulevard, Bryansk, 241035, Russia \\ E-mail: aishvyrkov@ rambler.ru
}

\begin{abstract}
The article deals with the problem of the relationship between intellectuals and authority. In many ways this problem comes down to the fact that politicians do not listen to the intellectuals' advice. But why don't they do? Perhaps it happens due to a significant difference in the mindset of politicians and intellectuals. The way intellectuals think is primarily determined by political theory. The theory is characterized by the primacy of consistency, completeness, subordination to abstract,
\end{abstract}


often «ideal» (in moral terms), principles and goals. As for the actions of politicians for various reasons they often deviate significantly from the parameters set by the theory in their behavior. In turn, intellectuals usually are not involved in political action as actors, that is, they cannot evaluate the actions of politicians except from the point of view of the theory. As a result, actions of politicians often lead to unsatisfactory results, both from the point of view of intellectuals (that is, from the point of view of theory and abstract principles on which it is based) and of politicians themselves. The author sees a way out in that the intellectuals, at least in their communications with politicians, must sacrifice part of the abstract principles on which theories are based or at least not to insist on their strict compliance by politicians. They should also try to reduce their demands concerning the consistency of political activity. This, of course, does not mean that they have to artificially primitivize their thinking or «morally fall». It's about not to expect and, most importantly, not to demand more rigorous thinking from society as a whole and politicians in particular than that they are capable of.

Keywords: intellectuals, politicians, power, theory, abstract principles.

For citation: Shvyrkov A.I. 2021. Intellectuals and Power: Another Look or Analysts and Politicians. 48 (2): 486-496 (in Russian). DOI: 10.52575/2687-0967-2021-48-2-486-496.

Интеллектуалы не хотят власти.

Интеллектуалы хотят, чтобы власть делала то, что они говорят.

В настоящее время стало почти общим местом констатировать сущностный кризис современной мир-системы [Туроу, 1999; Валлерстайн, 2003; Валлерстайн, 2005; Розов, 2019; Greenspan, 2008]. При этом большинство исследователей сходятся во мнении, что предсказать, как именно будут развиваться события, практически невозможно. Можно предположить, что это во многом обусловлено тем, что мы не имеем в своем распоряжении достаточного количества развитых теорий, которые могли бы использовать для того, чтобы делать уверенные социологические, экономические и прочие прогнозы.

Проблема, однако, не только в том, что теории «не хватает». Проблема также в том, что даже та теория, которая имеется, очень часто не используется в полном объеме (а то и не используется вовсе).

Одно из возможных объяснений этого может состоять в том, что те, кто принимают политические решения, просто не знакомы с необходимой (причем уже существующей) теорией. Они также часто не слушают тех, кто с теорией знаком. То есть не слушают интеллектуалов. Но почему же интеллектуалов не слушают? И, главное, как с этим быть?

В данной статье, таким образом, речь пойдет о взаимоотношениях власти или, точнее, политиков и интеллектуалов, о том, каким образом вторые могут воздействовать на первых. Поскольку тема эта, похоже, не собирается терять свою актуальность [Дьяков, 2019; Drake, 2003; Giesen, 2011; Elshtain, 2014; Vossen, 2015], надеюсь, мой скромный вклад не пропадет втуне.

По моему мнению, для того чтобы ответить на сформулированные выше вопросы, важно прояснить следующий момент.

Помимо прочего, все люди различаются тем, на какое «интеллектуальное расстояние» они «видят», на какую глубину способны анализировать ту или иную проблему. В количественном отношении это может выражаться в том, сколько теорий знает тот или иной человек и сколько фактов он может под них подвести (предсказания в результате подведения фактов под теории должны таким образом получаться автоматически). 
Важно понимать, что речь в данном случае не идет о пресловутой интуиции. Речь идет о тех прогнозах, которые всегда можно исчерпывающе объяснить, опираясь на соответствующую теорию.

Реакция на те или иные события того или иного человека непосредственно зависит от глубины анализа, на который этот человек способен, от того, насколько шагов он может просчитывать. Тот, кто «видит дальше», то есть тот, кто способен просчитывать на большую глубину, соответственно и реагирует на более отдаленные события.

Что значит «реагировать»? Это значит, по крайней мере, говорить о грядущих (предсказываемых) событиях, их последствиях. Причем говорить публично, апеллируя как к элитам, так и к широкой публике. Речь о призывах принять те или иные меры (например, принять тот или иной закон).

Однако, реагируя на эти на самом деле еще не наступившие события, тот, кто «видит дальше», как бы действует в совершенно ином временном масштабе, он как бы ускоряет время, или, точнее, пропускает, выбрасывает тот промежуток времени, через который эти события должны (или могли бы) произойти. То есть события эти становятся для него настоящим.

Поскольку другие люди не могут видеть так же далеко, поведение такого «дальнозоркого», его реакция, его иногда паника оказываются им непонятны. Вследствие этого они просто не видят смысла действовать так, как им предлагают действовать «дальнозоркие».

Фразу о глубине анализа следует понимать, так сказать, в ограниченном смысле: результат анализа здесь во внимание не принимается. Главное, что человек способен на такой анализ. Почему глубина анализа понимается именно таким образом, станет понятно из дальнейшего.

Описанный выше механизм ответственен за многие недоразумения, возникающие в отношениях между аналитиками и политиками, между учеными и «профанами», теоретиками и практиками. Суть его в том, что, образно выражаясь, аналитики и политики живут по разным часам. Те события, которые для первых - чуть ли не настоящее, для вторых - очень отдаленное, может быть, даже нереальное будущее. Однако проблема в том, что ресурсы, рычаги управления обществом, экономикой, государством, как правило, находятся в руках практиков. Почему именно так тема для отдельного разговора. Хочу лишь добавить, что, как правило, «критическая масса» «дальнозорких» теоретиков, которая была бы достаточна для того, чтобы влиять на «близоруких» практиков, накапливается не часто. Нередко ученые (эксперты, аналитики и прочие) вынуждены буквально навязывать себя и свои услуги.

Итак, дальнозоркие интеллектуалы либо создают теории, либо активно ими пользуются. Любая теория - просто в силу особенностей ее создания, в силу бытия теорией - обладает свойствами законченности, системности, последовательности и т. п. Любая теория также базируется на тех или иных принципах, которые связывают все части теории воедино. Если речь идет о политических теориях, то для многих из них характерно подчинение всех ее положений какому-то одному абстрактному, часто «идеальному» (в моральном отношении) принципу. Например, справедливости, общего блага, гармонии, прогресса и проч. В качестве объединительного, системообразующего начала в них также может выступать образ некоего желаемого состояния общества, государства, «системы». В стремлении к осуществлению этого образа им видится смысл политики и существования человеческого общества.

Поскольку теории (такие теории) важны для интеллектуалов, поскольку созданию и распространению теорий посвящена значительная часть их жизни, мышление в 
терминах теории становится для них чуть ли не основным типом мышления. По крайней мере, тогда, когда речь идет о тех предметах, которые толкуют теории. Можно сказать, что они, интеллектуалы, не могут - уже не могут - мыслить о реальности какимлибо иным образом, считают, что мыслить о реальности по-другому - это значит мыслить неправильно. Более того, действия других людей - в том числе тех, кто не знаком с теорией (и поэтому ею не руководствуется) - они также оценивают почти исключительно с точки зрения теории. И эти действия, естественно, тоже часто представляются им неправильными (опять же с точки зрения теории).

Поскольку интеллектуалы чаще всего уверены в верности своих теорий (по крайней мере, в том, что если есть теория, то лучше действовать в соответствии с нею), они часто бывают возмущены, раздосадованы, сбиты с толку действиями политиков, теории не соответствующими.

Пожалуй, еще бо́льшую досаду у них вызывает то, что политики отказываются руководствоваться абстрактными, «идеальными» принципами, идеями, которые положены в основу многих политических теорий (например, идеей общего блага).

Важно понимать, что, попади интеллектуалы в «политическую ситуацию», они, вполне возможно, и сами бы не стали такими идеями руководствоваться (а если бы и стали, то, скорее всего, быстро бы «прогорели»). Однако поскольку они, как правило, в подобные ситуации не попадают (потому что избегают активной вовлеченности в политический процесс - говорю это, кстати, без всякого осуждения), им остается только оценивать действия политиков со стороны. Но оценивать такие действия они могут только (или преимущественно) с точки зрения теории, часто - «идеальных» принципов, потому что, повторюсь, они не могут мыслить иначе, чем с точки зрения теории. В их мышлении и, пожалуй, что еще важнее, в их суждениях (в том числе публичных) «идеалы» оказываются имеющими вес гораздо больший, чем тот, который эти идеалы, возможно, имеют для политиков (о весе этих идеалов для политиков интеллектуалы, очевидно, могут судить по их, политиков, делам - другой вопрос, насколько точно судить).

Что важно учитывать, в том числе и в связи со сказанным выше? Во-первых, то, что интеллектуалы действительно часто оказываются правы в своих оценках, прогнозах и т. п. То есть их «паника» оказывается вполне оправданной. Часто в отношении подобных случаев мы также можем констатировать, что меры, которые принимались (если вообще принимались) политиками в ответ на предупреждения интеллектуалов, оказывались запоздалыми.

Во-вторых, учесть следует и то, что интеллектуалы нередко ошибаются. Во многом это связано с несовершенством теории. Поэтому, когда политики не следуют их, интеллектуалов, советам, это не значит, что их ждет «неудача».

Термин «неудача» в последней фразе можно понимать двояко (поэтому соответствующее слово и взято в кавычки).

В первом случае тот или иной результат действий политиков будет неудачей в том смысле, что он не будет удовлетворять интеллектуалов, оценивающих этот результат с точки зрения теории (например, с точки зрения достижения «общего блага», причем общее благо понимается так, как оно понимается в теории). При этом самих политиков полученный результат может вполне устраивать. Во втором случае данный термин необходимо понимать так, что неследование советам интеллектуалов может приводить к успеху и с точки зрения теории. Этот последний момент, очевидно, можно отнести как раз на счет слабости, несовершенства теории.

Рассмотренное выше позволяет нарисовать следующую типичную ситуацию.

В политической сфере те или иные решения, как правило, принимаются людьми, «зрение» которых далеко от «единицы» (в вышеприведенном смысле). Они обладают далеко не самыми систематизированными представлениями об устройстве государства 
и общества. Эти их представления также далеко не всегда структурированы сообразно некому абстрактному принципу. По крайней мере, если судить по их, этих людей, действиям. Решения этих людей приводят к определенным последствиям. Последствия формируют объективные тенденции. Эти тенденции в свою очередь улавливают аналитики, ученые, философы и т. п. (то есть «дальнозоркие»). Последние пытаются проанализировать данные тенденции, определить, к чему они могут привести, сформулировать рекомендации, следование которым, как им кажется, должно помочь в будущем избежать тех негативных последствий, к которым, по мнению «дальнозорких», ведут действия политиков.

Однако эти рекомендации (как и оценка решений политиков, последствий этих решений), основаны на представлениях, которые во многих отношениях чужды «близоруким» политикам (если, повторяю, судить по их делам). Чужд им и тот способ, которым эти представления систематизируются, структурируются. Им чужд тот «верховный принцип», которым они подчинены.

Следствием этих моментов является то, что политики могут, во-первых, подругому (т. е. не так, как аналитики, интеллектуалы) оценивать последствия тех или иных своих решений, во-вторых, неправильно воспринимать степень временно́й близости этих последствий и, в-третьих, соответственно, не видеть смысла следовать советам интеллектуалов.

Необходимо отметить, что я отнюдь не считаю, будто ученые, философы, аналитики, вообще, интеллектуалы («дальнозоркие») в том или ином смысле «правильнее» политиков («близоруких»). Хотя мои симпатии, пожалуй, в большинстве случаев будут находиться на стороне первых (отчасти потому, что в своих прогнозах они действительно нередко оказываются правы, отчасти потому, что именно к «дальнозорким» я отношу себя). Также хочу подчеркнуть, что я не отрицаю возможности существования индивидов, в которых способность к действию и научному прогнозу развиты в равной степени.

Однако есть еще один важный момент, касающийся прогнозов и их результативности, на который следует обратить внимание. С одной стороны, он еще больше «запутает» ситуацию, а с другой, возможно, сделает наше отношение к неследованию рекомендациям аналитиков не таким алармистским.

Итак, предположим, что аналитики выдали некоторый прогноз, касающийся развития той или иной политической ситуации. Причем прогноз при сохранении актуальных на его момент тенденций негативный. И пусть аналитиков не послушались (по разным причинам - например, по одной из тех, что были описаны выше).

Предположим также, что прогноз является достаточно обоснованным, то есть основанным не на «интуиции», «опыте», «чутье», а на вполне серьезной, качественной теории (то есть аналитик может свой прогноз в достаточной мере объяснить, апеллируя к этой теории).

Наконец, пусть этот прогноз касается достаточно отдаленных событий (отстоящих от момента, когда был дан прогноз, хотя бы на 1-2 года).

Описанная ситуация является для аналитика почти идеальной (если, конечно, не считать того, что его не послушались). Идеальной в том смысле, что у аналитика есть все основания надеяться, что прогноз сбудется. Однако есть несколько обстоятельств, которые несколько меняют нарисованную картину.

Дело в том, что в случае, если предсказываемые события достаточно серьезны, глобальны (например, если речь идет о революции или просто смене режима), касаются значительных масс населения, причем, по прогнозам, должны произойти «не завтра», то, как правило, никакой аналитик никогда не может учесть того, что:

1) обязательно произойдут некие важные и принципиально непредсказуемые события, как благоприятствующие реализации прогноза, так и неблагоприятствующие 
(например, может измениться экономическая или политическая конъюнктура, произойдет стихийное бедствие и т. п.); подчеркну, что подобные события произойдут обязательно - просто в силу того, что любая политическая система находится в очень сложной, «обширной» и потому принципиально непредсказуемой среде;

2) люди, которых касается прогноз (например, ассоциируемые с правящим режимом), способны менять свое поведение, если и не делая наступление предсказанного события невозможным, то хотя бы существенно оттягивая момент его наступления (например, авторитарный режим может ослабить свое давление на общество, тем самым отдаляя момент начала протестов).

Комбинированное действие этих двух факторов, очевидно, способно «уничтожить» любой, даже самый обоснованный прогноз.

Хочу подчеркнуть, что описанный гипотетический случай не является «только» случаем. На самом деле он является иллюстрацией важной закономерности: когда речь заходит о глобальных политических прогнозах, следует всегда помнить, что непредсказуемые, «случайные» обстоятельства (любой природы) появляются закономерным образом, то есть всегда (хотя мы можем и не знать, какими именно они будут). Причем эта непредсказуемость связана не со «слабостью» теории (или аналитиков), а со сложностью мира. Пользуясь термином Н. Талеба, эту мысль можно выразить так: черные (или белые) лебеди прилетают всегда [Талеб, 2019].

Это обстоятельство с одной стороны, очевидно, снижает роль прогноза, а с другой - дает нам основания не слишком переживать по этому поводу, дает надежду на то, что не слушать аналитика - это не всегда зло. Будущее далеко не всегда оказывается настолько печальным, как предсказывают аналитики, причем даже в том случае, когда их не слушают. Хотя, повторюсь, лучше их все-таки слушать. слушать?

Какими же должны (могут) быть условия, при которых интеллектуалов станут

Прежде всего, «класс» интеллектуалов-аналитиков должен обладать субъектностью. Интеллектуалы-аналитики должны осознавать себя как группу со своими особыми интересами, осознавать «свое право» и ценность. Не бояться отстаивать свои интересы. Например, с помощью организации в профсоюзы. Однако это лишь «рамочные условия», условие необходимое, но не достаточное: это же условие должно выполняться в случае любой социальной группы для того, чтобы с ней считались, чтобы ее услышали. В случае «класса аналитиков» ситуация, очевидно, сложнее, поскольку этот «класс» хочет не только отстоять свои узкоклассовые интересы, но и претендует на определенный вид руководства обществом в целом (причудливую форму такого руководства или претензии на него я попытался отразить в эпиграфе к этой статье). То есть перед ними стоит гораздо более серьезная задача, чем та, которая стоит, например, перед шахтерами, водителями троллейбусов или даже полицейскими (у которых тоже, как известно, есть профсоюзы). Это делает «класс аналитиков» схожим с «классом политиков». Однако на этом сходство, пожалуй, и заканчивается.

Аналитики хотят (чаще всего) влиять на жизнь общества, советуя власть имущим (при этом часто не желая брать ответственность за рекомендуемые решения), то есть опосредованно, а не напрямую. Они избегают обращаться к «толпе», предпочитая более спокойную обстановку и более «адекватных» слушателей.

У них есть некий идеал политика, с которым им хотелось бы иметь дело. С одной стороны, он должен быть «всемогущим», способным совладать с «толпой», а с другой - восприимчивым к «голосу разума», олицетворяемому, по мнению аналитиков (кстати, не без оснований), ими самими. И уважительным, признающим за аналитиками право на собственное достоинство, уважающим это мнение и самих аналитиков. 
Чаще всего аналитики оказываются разочарованы и политиками как таковыми, и отношением к ним со стороны политиков. Не сумев обрести субъектность, не сумев заставить с собой считаться, они либо «идут в услужение», становятся трансляторами, оформителями воли «политического класса», либо вообще устраняются от участия в политике. Пример первого случая дает СССР, где интеллектуалы, «сотрудничавшие» с властью, работали на оформление и продвижение коммунистической идеологии (но не создавали еe!), пример второго - сегодняшняя Россия, где к подобной деятельности (а также технологической реализации политических решений) «допущены» лишь единицы.

Отсутствие налаженных коммуникаций между властью и классом аналитиковинтеллектуалов, как правило, довольно быстро приводит к тому, что я называю «синдромом бедного дискурса». Суть этого синдрома состоит в следующем.

Если интеллектуалы лишены возможности достаточно плотно общаться с политиками, если интеллектуал не может стать политиком (принеся в политику свой «интеллектуалистский» взгляд на мир), действующие политики часто оказываются неосведомлены в достаточной степени о новых политических теориях, - теориях, релевантных современной им политической реальности, теориях, предлагающих решения актуальных политических проблем, обеспечивающих политиков адекватным словарем. В результате дискурс, продуцируемый политиками, оказывается несовременным, неадекватным реальности, базирующимся на очень ограниченном количестве устаревших (как правило) теорий, то есть беднылм. Политики утрачивают «контакт» с «массами», мировым политическим сообществом, становятся в лучшем случае способными лишь имитировать современный политический дискурс.

Однако предположим, что некоторую степень «уважения» аналитическому сообществу все же удалось добиться, то есть что его начали слушать. Значит ли это, что его начнут слушаться? Как следует из сказанного в первой половине данной статьи, автоматически этого не случится. Нужны дополнительные меры (со стороны аналитического сообщества).

Можно предположить, что насилие - это не в духе интеллектуалов. Да у них, как правило, и нет средств заставить кого-то (тем более - политиков) делать то, что они, интеллектуалы, считают нужным. Их оружие - слово. Они должны - раз уж им удалось добиться того (как мы предположили), чтобы их выслушали - убедить в своей правоте. Однако, как также уже было сказано, мышление и язык их таковы, что сделать это у них вряд ли получится: их просто не поймут. Что же делать? Очевидно, им следует как-то модифицировать свой дискурс. Но как?

Исходить, вероятно, следует из приведенного выше описания особенностей мышления политиков (коль скоро именно политиков нужно убеждать, на политиков нужно влиять). Напомню, что речь шла в частности о том, что политики, если судить по их действиям, не слишком склонны руководствоваться абстрактными принципами (добра, справедливости и т. п.). Их действия скорее больше соответствуют представлениям политического реализма [Walzer, 1972; Bellamy, 2010; Galston, 2010]. Поэтому и обращаться к ним, апеллируя к этим абстрактным принципам, смысла нет.

Следует заметить, что такая особенность мышления, шире - менталитета - политиков - это не плохо и не хорошо. Реальность - политическая реальность - слишком сложна для того, чтобы «добрые намерения» всегда приводили к аналогичным результатам. Не зря же говорят, что такими, то есть добрыми, намерениями выложена дорога в ад. Думаю, это высказывание по отношению к политике справедливо как ни к какой другой сфере. Возможно, что следование политической конъюнктуре, «оппортунизм» и т. п. довольно часто являются самой здоровой стратегией (это следует, в частности, из приведенных выше рассуждений о черных и белых лебедях). 
Также должен заметить, что, когда я говорю об обращении к политикам, я имею в виду не только прямые обращения. Речь идет и об обращениях косвенных - например, через политические теории, которые, таким образом, также хорошо бы модифицировать. Думаю, это только пойдет им на пользу. Как кажется, наши сегодняшние политические теории слишком отягощены наследием этических теорий, созданных сотни, а то и тысячи лет назад. Мы часто склонны обвинять политиков в аморальности, однако, возможно, проблема здесь не только в собственно их, политиков, аморальности [Швырков, 2013]), но и в том, что наши взгляды на природу морали требуют пересмотра.

Еще одна модификация, которой хорошо бы подвергнуть дискурс аналитиков, связана со степенью его структуризации: ее следует по возможности ослабить, точнее, ей не стоит придавать слишком большого значения. В частности, это может выражаться в том, чтобы не особенно беспокоиться по поводу строгой логической согласованности разных «месседжей», обращенных к политикам. Главное, чтобы сами эти месседжи были достаточно эффектными и обоснованными. Что касается «глубинных» связей между ними, то рассмотрение их следует оставить для научных конференций.

Кто-то мог бы заметить, что, следуя подобным принципам, интеллектуалам придется «наступать себе на горло», «ломать себя через колено» и т. п. С одной стороны, это замечание не лишено оснований, с другой - следовало бы напомнить, что интеллектуал, который хочет в чем-то убедить политика, действует не только как ученый, эксперт и т. п., но и как гражданин. И как гражданин он должен действовать, сообразуясь не только со своими личными предпочтениями, но и общественным благом. Общественное же благо предполагает некоторые жертвы.

Однако можно взглянуть на эту проблему и под другим углом.

Эта проблема (убеждения политиков) сходна с той проблемой, с которой сталкиваются начинающие копирайтеры, когда им нужно написать убедительный продающий текст.

Будучи людьми сравнительно образованными, они часто пишут тексты слишком сложные (и длинные) для большей части их потенциальной аудитории (кстати, сложные и длинные не только из-за низкого интеллекта этой аудитории, но и из-за тех условий, в которых эти тексты воспринимаются, условий, которые не позволяют «вникнуть» и т. п.). Естественно, эти тексты оказываются неспособны что-либо «продать». И только когда копирайтер начинает принимать во внимание особенности менталитета своей потенциальной аудитории, условия, в которых воспринимаются его тексты, у него появляется шанс на успех. Благо, современный маркетинг неплохо изучил этот менталитет и предложил некоторое количество простых правил, которые, если им следовать, способны буквально творить чудеса. Хорошо бы разработать такие правила для текстов, обращенных к политикам.

И последнее. Чтобы не создалось впечатление, будто я лишь ограничиваюсь благими пожеланиями, сам оставаясь в стороне от реализации предложенных принципов, замечу, что я уже довольно давно предпринял ряд попыток их применения на практике - собственно, еще до того, как изложенные выше идеи сложились в подобие концепции [Швырков, 2012]).

Итак, в своей статье я обратился к проблеме отношения интеллектуалов и политиков. Во многом эта проблема сводится к тому, что политики не слушают советов интеллектуалов. Однако почему же они их не слушают?

Отчасти это связано с тем, что политикам это просто не выгодно. А также с тем, что последствия тех или иных политических решений, которые интеллектуалы рассматривают как негативные и для избежания которых предлагают меры, политики негативным не считают (и, соответственно, не видят смысла принимать меры для недопущения этих последствий). Однако эти причины не единственные. Не менее важной мне видится следующая. 
Возможно, частая «глухота» политиков в отношении предостережений интеллектуалов обусловлена существенной разницей в типе мышления тех и других. То, как мыслят интеллектуалы, преимущественно определяется политической теорией. Теория же характеризуется приматом системности, завершенности, подчиненности абстрактным, часто «идеальным» в моральном отношении принципам и целям. Последнее, очевидно, характерно для многих политических теорий. Что касается действий политиков, то они - по разным причинам - часто существенно отклоняются от тех параметров, которые задает теория. В свою очередь, интеллектуалы, как правило, не вовлечены в политическое действие в качестве а́кторов, то есть они не могут оценивать действия политиков иначе, чем с точки зрения теории. Например, на основании собственного опыта политической деятельности. В результате всего этого действия политиков часто приводят к неудовлетворительным как с точки зрения интеллектуалов (то есть с точки зрения теории и тех абстрактных принципов, на которых они основаны), так и самих политиков результатам.

Выход их данной ситуации я вижу в том, что интеллектуалы должны, по крайней мере, в своих коммуникациях с политиками пожертвовать частью тех абстрактных принципов, на которых основаны теории, или хотя бы не настаивать на их жестком соблюдении политиками. Им также следует попытаться уменьшить свои требования в отношении системности и последовательности действий политиков. Речь, разумеется, идет не о том, чтобы искусственно примитизировать свое мышление или «опускаться» в моральном отношении, речь идет о том, чтобы не ожидать и, главное, не требовать от общества в целом и политиков в частности большей строгости мышления и в следовании теории, чем та, на которую они в принципе способны.

\section{Список литературы} $368 \mathrm{c}$.

1. Валлерстайн И. 2005. Конец знакомого мира: Социология XXI века. М., Логос,

2. Валлерстайн И. 2003. После либерализма. М., Едиториал УРСС, 256 с.

3. Дьяков А.В. 2019. Политическая функция интеллектуала: история и современность. Полис. Политические исследования, 1: 21-32.

4. Леви-Строс К. 2001. Структурная антропология. М., Изд-во ЭКСМО-Пресс, 512 с.

5. Мангейм К. 2000. Проблема интеллигенции. Исследования ее роли в прошлом и настоящем. В кн.: Мангейм К. Избранное: Социология культуры. М.; СПб.: Университетская книга: 94-233.

6. Поппер К. 1992. Открытое общество и его враги: в 2 т. М.: Феникс, Культурная инициатива.

7. Розов Н.С. 2019. Эпохи турбулентности и их преодоление. Полития. 1: 81-96.

8. Талеб Н. 2019. Черный лебедь. Под знаком непредсказуемости. М., КоЛибри, 736 с.

9. Туроу Л. 1999. Будущее капитализма. Новосибирск: Сибирский хронограф, 432 с.

10. Хилсмэн Р. 1957. Стратегическая разведка и политические решения. М., Иностранная литература, 192 с. $119-130$.

11. Швырков А.И. 2013. Почему обществом управляют аморальные люди. Полития, 3 :

12. Швырков А.И. 2016. Теория, дискурс и политическая реальность. Часть 2. Политическая концептология, 2: 23-103.

13. Швирков O.I. 2012. Партія ФПГ та громадянське суспільство. Вісник Харківського національного університету ім. В.Н. Каразіна, 1007: 136-139.

14. Bellamy R. 2010. Dirty hands and clean gloves: Liberal ideals and real politics. European Journal of Political Theory, 9 (4): 412-430.

15. Drake D. 2003. Sartre: Intellectual of the Twentieth Century. In: Sartre Studies International. An Interdisciplinary Journal of Existentialism and Contemporary Culture, 2: 29-39.

16. Elshtain J.B. 2014. Why Public Intellectuals? The Wilson Quarterly, 1: 76-88. 
17. Galston W.A. 2010. Realism in political theory. European Journal of Political Theory, 9 (4): 385-411.

18. Giesen B. 2011. Intellectuals and Politics. Nations and Nationalism, 2: 291-301.

19. Greenspan A. 2008. The Age of Turbulence: Adventures in a New World. New York: Penguin Press, 608 p.

20. Vossen B. van der. 2015. In Defence of the Ivory Tower: Why Philosophers should stay out of Politics. Philosophical Psychology, 7: 1045-1063.

21. Walzer M. 1972. Political Action: The Problem of Dirty Hands, Philosophy and Public Affairs 1: 35-47.

\section{References}

1. Wallerstein I. 2003. Posle liberalizma [After liberalism]. Moscow, URSS editorial, 256 p. (in Russian).

2. Wallerstein I. 2005. Konets znakomogo mira: Sotsiologiya XXI veka [The End of a Familiar World: Sociology of the 21st Century]. Moscow, Logos, 368 p. (in Russian).

3. D'yakov A.V. 2019. The political function of the intellectual: history and modernity. Policy. Political research. 1: 21-32 (in Russian).

4. Levy-Stros K. 2001. Strukturnaya antropologiya [Structural Anthropology]. Moscow: Izd-vo EKSMO-Press, 512 p. (in Russian).

5. Mannheim K. 2000. Problema intelligentsii. Issledovaniya yeye roli v proshlom i nastoyashchem [The Problem of Intelligentsia. Studies of its Role in the Past and the Present]. In: Mannheim K. Izbrannoye: Sotsiologiya kul'tury [Selected works: Sociology of Culture]. Moscow; St. Petersburg: Universitetskaya kniga: 94-233 (in Russian).

6. Popper K. 1992. Otkrytoye obshchestvo i yego vragi: v 2 t. [Open Society and its Enemies: in 2 vols]. Moscow: Feniks, Kul'turnaya initsiativa (in Russian).

7. Rozov N.S. 2019. Epohi turbulentnosti i ih preodolenie [Epochs of turbulence and their overcoming]. Polity, 1: 81-96 (in Russian).

8. Turrow L. 1999. Budushcheye kapitalizma [The future of capitalism]. Novosibirsk: Sibirskiy khronograf, 432 p. (in Russian).

9. Taleb N. 2019. Chernyy lebed'. Pod znakom nepredskazuyemosti [The Black Swan: The Impact of the Highly Improbable]. Moscow: KoLibri, 736 p. (in Russian).

10. Hillsman R. 1957. Strategicheskaya razvedka i politicheskiye resheniya [Strategic Intelligence and Political Decisions]. Moscow: «Inostrannaya literatura», 192 p. (in Russian).

11. Shvyrkov A.I. 2013. Pochemu obshchestvom upravlyayut amoral'nye lyudi [Why Immoral People Rule Society]. Politia, 3: 119-130 (in Russian).

12. Shvyrkov A.I. 2016. Teoriya, diskurs i politicheskaya real'nost' [Theory, discourse and political reality]. Part 2. Political Conceptology, 2: 23-103 (in Russian).

13. Shvyrkov O.I. 2012. Partiya FPG ta gromadyans'ke suspil'stvo [FIG Party and Civil Society]. Visnyk Kharkivs'koho natsional'noho universytetu im. V.N. Karazina, 1007: 136-139 (in Ukrainian).

14. Bellamy R. 2010. Dirty hands and clean gloves: Liberal ideals and real politics. European Journal of Political Theory, 9 (4): 412-430.

15. Drake D. 2003. Sartre: Intellectual of the Twentieth Century. In: Sartre Studies International. An Interdisciplinary Journal of Existentialism and Contemporary Culture. 2: 29-39.

16. Elshtain J.B. 2014. Why Public Intellectuals? The Wilson Quarterly. 1: 76-88.

17. Galston W.A. 2010. Realism in political theory. European Journal of Political Theory, 9 (4): 385-411.

18. Giesen B. 2011. Intellectuals and Politics. Nations and Nationalism, 2: 291-301.

19. Greenspan A. 2008. The Age of Turbulence: Adventures in a New World. New York: Penguin Press, 608 p.

20. Vossen B. van der. 2015. In Defence of the Ivory Tower: Why Philosophers should stay out of Politics. Philosophical Psychology, 7: 1045-1063.

21. Walzer M. 1972. Political Action: The Problem of Dirty Hands, Philosophy and Public Affairs 1: 35-47. 
Via in tempore. История. Политология. 2021. Том 48, № 2 (486-496)

Via in tempore. History and political science. 2021. Vol. 48, No. 2 (486-496)

ИНФОРМАЦИЯ ОБ АВТОРЕ

Швырков Александр Иванович, кандидат философских наук, доцент кафедры гуманитарных и социальных дисциплин Брянского государственного технического университета, г. Брянск, Россия

\section{INFORMATION ABOUT THE AUTHOR}

Shvyrkov Alexander Ivanovich, Phd in Philosophy, Associate Professor of the Department of Humanities and Social Disciplines, Bryansk State Technical University, Bryansk, Russia 